\title{
Moderating Effects of Teachers' Teaching Experience on Home Learning Associated with Literacy Skills among Chinese Preschoolers
}

\author{
Chan Mei Yee ${ }^{1} \&$ Zarinah Arshat ${ }^{1}$ \\ ${ }^{1}$ Faculty of Human Ecology, Universiti Putra Malaysia, Seri Kembangan, Selangor, Malaysia \\ Correspondence: Zarinah Arshat, Department of Human Development and Family Studies, Faculty of Human \\ Ecology, Universiti Putra Malaysia, 43400 UPM Serdang, Selangor Darul Ehsan, Malaysia. E-mail: \\ zarinah_upm@upm.edu.my
}

Received: July 27, 2015 Accepted: November 25, 2015 Online Published: January 12, 2016

doi:10.5539/ass.v12n2p23 URL: http://dx.doi.org/10.5539/ass.v12n2p23

\begin{abstract}
This study was designed to determine the influence of home learning on Chinese preschoolers' literacy skills is likely to be moderated by the level of teacher's teaching experience. There were 136 preschoolers aged ranged between three to six years old with their parents and teachers recruited in this study using a Multi-Stage Cluster sampling technique. The results of the Hierarchical Multiple Regression analysis indicate that teacher's teaching experience has a significant moderating effect on the strengths of the relationship between home learning and preschoolers' literacy skills. Further research is needed to investigate more deeply to identify whether these relationships are upheld over time and with diverse sample.
\end{abstract}

Keywords: home learning, literacy skills, teacher's teaching experience

\section{Introduction}

As children enrol into formal schooling, they are facing numerous challenges. As such, they need to equip themselves well physically and cognitively to cope with the new challenging situation in school. School teachers have established expectations on children's basic literacy ability. Given this expectation, teachers somewhat rigidly conduct their lessons according to a well-structured course syllabus. Unfortunately, children who have poor literacy may struggle with reading and writing in class. Consequently, they tend to receive less practice in reading and less contact with the content of knowledge, vocabulary and other language skills (Gullo, 2013; Shanahan \& Shanahan, 2012; Lonigan, Farver, Phillips \& Clancy-Menchetti, 2011). Literacy skills should be established in young children at an early age as they begin to develop language abilities, especially in preschool years. Improving children' literacy skills is considered important to be studied because possessing a good basic literacy skills can enhance their later development in learning process, further reducing the incidence of school dropouts.

Psychologist agree that family especially parents is a significant contributor to children's literacy skills (Bronfenbrenner, 1979) and learning to read and write can emerge naturally when supported by adults (Vygotsky, 1978). For instance, existing studies (Niklas \& Schneider, 2013; Farver, Xu, Lonigan, \& Eppe, 2013) indicate that parents participate in home literacy activities and involvement in learning process can enhance children's literacy skills. Likewise, preschool teachers are also described as crucial facilitators of children's early reading. Several educational researches had established that improving teacher quality is a successful way to improve student achievement especially in terms of reading and writing (Giles \& Tunks, 2014; Son, Kwon, Jeon, \& Hong, 2013). The experience teachers are more likely to equip themselves to be more effective in teaching, further, facilitate literacy development in children (Son, Kwon, Jeon, \& Hong, 2013).

\subsection{Statement of Problem}

Malaysia is one of the countries in the world which have three major races which are Malay, Chinese and Indian. Indeed, all Malaysian are used at least two languages in the education system. The Malaysia Education System requires all students in primary and secondary schools learn English language as an official second language except the main native language.

Particularly, Chinese students' have difficulties in learning English because the syllabus and pronunciation of their mother language such as Cantonese and Mandarin are very different with English (Li \& Tan, 2015; Abidin, 
Pour-Mohammadi \& Ooi, 2011; Phoon \& Abdullah, 2010). Hence, English language learning process is somehow tricky than others races in Malaysia. In the sense, Chinese students who are not performing well in English subject will feel upset further less interest in learning.

In Malaysia, the National Education Blueprint 2006-2020 indicate that 4.4\% of primary school students had not mastered the basic literacy skills especially reading. Some more, there are 54.000 Year One students without basic reading skills (Source: KIA2M for literacy rates, 2009). This fact is considered a serious problem and alarming the local government to pay more attention to this dilemma.

\subsection{Objectives of the Study}

As mentioned earlier, literacy acquisition is a key in leading individuals to succeed in later learning and academic performance. In summary, understanding of the importance and predictors of preschoolers' literacy skills is needed to enhance children's later learning in formal schooling. Ecology theory and reviewed literature have indicated that home learning and teacher's teaching experience do effect the development of children. Hence, the present study examined how well home learning and teachers' teaching experience associated with the literacy skills among Chinese preschoolers.

The general objective of this study is to determine the moderating effect of teachers' teaching experience in the relationship between home learning environment and child's task-focused behaviour in school with literacy skills.

\section{Method}

\subsection{Samples and Procedure}

The sample consists of 136 Chinese preschoolers with age range between three to six years old with their parents from three selected districts in the urban area of Selangor recruited in this study by using a Multi-Stage Cluster sampling technique.

Prior to data collection, approval were obtained from the selected kindergarten's principal. The current study only selected three districts from urban area in Selangor which are Hulu Langat, Petaling, and Klang. Specifically, only one town or residential area was randomly selected from a large number of residential areas in each district due to the availability of study resources such as finance and manpower. Further, three kindergartens were randomly chosen from each selected residential area in that particular district. The preschoolers were being interviewed face-to-face by the researcher. At the end of the interview session, the preschoolers were given a lollipop as a token of appreciation for their participation in this study.

\subsection{Research Design}

This study is a cross-sectional survey where the data and information are collected at one point in time from a sample selected to represent a larger population (Leedy \& Ormrod, 2005). The respondents were observed from a defined time and were asked to answer a set of self-administered questionnaire which was used to collect the information relevant to the study.

\subsection{Measures}

Social-Demographics information was collected from the parents and teachers. Parents were asked to indicate their family monthly income, number of children in home, their spouse and their education level. In the mean time, parents were also responded to personal information about their tested child in this study which includes age, gender, and birth order. In addition, teachers who teach the tested child were asked to indicate the number of years they have been teaching in kindergarten.

Home Learning or parental involvement in home-based activities was measured by the Home Learning Environment Questionnaire (HLEQ) (Lonigan \& Farver, 2002) which consists of three subscales: parents' literacy involvement with their children, parents' literacy habits and children's literacy interest. This is a self-administered questionnaire rated by the parents regarding their reading behaviour and reading activities with children at home. A total of 13 items which is rated on a five-point scale that ranges from $1=$ never to $5=$ daily. The reliability of the scale in this study was 0.86 which considered performing a high internal consistency for all the subscales.

Preschoolers' Literacy Skills was measured by Test of Early Reading Ability Third Edition (TERA-3) (Reid, Hresko, \& Hammill, 2001). It is a well-known and unique measure of the reading ability of young children between the ages of 3 years 6 months to 8 years 6 months. TERA-3 is the new version after the amendment and improvement on several limitations found in the previous versions. There are two picture booklets, namely Form A and Form B which consist of three subtests: alphabet, conventions, and meaning. The child will earns 1 point 
for each item passed and scored 0 for the incorrect items. Reading quotients indicated from 35 to 165 . Higher scores indicate higher level of reading skills. The Cronbach's alpha for TERA-3 in this study was 0.97.

\section{Results}

\subsection{Data Analysis}

Foremost, a descriptive analysis was conducted to provide a clearer picture of the data distribution. Second, the magnitude and strength of the relationships of the study variables were quantitatively by using Pearson Correlation. Later on, the Multiple Linear Regression was used to determine the best set of predictors of preschooler's literacy skills. Finally, the Hierarchical Multiple Regression Analysis was applied to examine the moderation effect of teachers' teaching experience on the relation between home learning and literacy skills among preschoolers.

\subsection{Descriptive Statistical Analysis}

\subsubsection{Child Personal, Family Characteristics and Teacher's Characteristics}

Results showed that about $47.1 \%$ of the preschoolers were five years old and almost half of them are boys. Further, the majority of them are first-born children in their families. Typically, most of them come from small families with only one or two children in their family. Most of the families' monthly income was within RM4000 which was considered sufficient for their household spending. On the whole, the parents were educated and had successfully completed eleven to twelve years of primary and secondary education. Moreover, about $36 \%$ of the parents classified themselves as performing a low level of home learning, while $35.2 \%$ were at medium level, and $28.7 \%$ of the parents practiced a high level of home-based learning activity. About half of the children attained average literacy scores. Meanwhile, all the teachers were educated and had an average teaching experience of about six years $(\mathrm{M}=6.92, \mathrm{SD}=4.71)$. Slightly half of the teachers $(58.1 \%)$ had more than five years' teaching experience, whereas $41.9 \%$ of the teachers had less teaching experience.

\subsection{Inferential Statistical Analysis}

3.3.1 Relationships between Child Personal and Family Characteristics, Home Learning, Teachers' Teaching Experience and Preschoolers' Literacy Skills

Correlational analysis was used to explore the relationships among the study variables in the study (Table 1). The results show that only the child's age was significantly related to their literacy skills $(r=0.17, p<0.05)$ for child personal characteristics factor. The correlation coefficient implied that the higher the child's age, the higher the literacy skills achievement. For family characteristics factor, there was a significant positive linear association between monthly household income with preschooler's literacy skills $(r=0.29, p<0.01)$. Children whose families earn high incomes tend to achieve higher literacy skills. Significant linear relationships were also found between family total monthly income with alphabet performance $(r=0.19, p<0.05)$, conventions performance $(r=0.30, p<0.01)$, and meaning performance $(r=0.18, p<0.05)$. The results of this study also showed that there were positive significant relationships between mothers' education level $(r=0.41, p<0.01)$ and fathers' education level $(r=0.37, p<0.01)$ with literacy skills. The findings indicated that if both the father and mother had a high level of education, their children were more likely to get a higher score in literacy. Further, fathers and mothers' education level also showed significant relationships with preschooler's alphabet performance $(r=0.27$, $p<0.01 ; r=0.39, p<0.01)$, conventions performance $(r=0.27, p<0.01 ; r=0.36, p<0.01)$, and meaning performance $(r=0.25, p<0.01 ; r=0.28, p<0.01)$. However, there was no linear relationship between child's sex, child's birth order, number of children with literacy skills.

Meanwhile, the findings illustrated that higher home learning practice was associated with higher level of preschooler's literacy skills $(r=0.45, p<0.01)$. When home learning activities increase, the preschooler's alphabet performance $(r=0.42, p<0.01)$, conventions performance $(r=0.33, p<0.01)$, and meaning performance $(r=0.44, p<0.01)$ also increase. Yet, the result of bivariate analysis as shown in Table 1 revealed that there was a weak and negative statistical correlation between teachers' teaching experience and preschoolers' literacy skills $(r=-0.17, p<0.05)$, conventions performance $(r=-0.21, p<0.05)$, and meaning performance $(r=$ $0.19, p<0.05)$. Preschoolers who had teachers with more teaching experience tend to perform lowly in literacy skills, conventions subtest, and meaning subtest. 
Table 1. Correlation between variables of study $(\mathrm{N}=136)$

\begin{tabular}{lcccc}
\hline \multicolumn{1}{c}{ Variables } & Literacy Skills & $\begin{array}{c}\text { Alphabet } \\
r(p)\end{array}$ & Conventions & Meaning \\
\hline Child Personal Characteristics & & & \\
Age & $.17(.05)^{*}$ & $.05(.56)$ & $.02(.84)$ & $.07(.43)$ \\
Sex & $-.04(.64)$ & $.04(.65)$ & $-.02(.84)$ & $-.15(.09)$ \\
Birth Order & $-.05(.59)$ & $.11(.20)$ & $1.12(.17)$ & $-.06(.59)$ \\
& & & & \\
Family Characteristics & & & & \\
Monthly Household Income & $.29(.00)^{* *}$ & $.19(.03)^{*}$ & $.30(.00)^{* *}$ & $.18(.04)^{*}$ \\
Number of Children & $-.13(.14)$ & $.04(.69)$ & $-.16(.06)$ & $-.18(.04)^{*}$ \\
Mothers' Education Level & $.41(.00)^{* *}$ & $.39(.00)^{* *}$ & $.36(.00)^{* *}$ & $.28(.00)^{* *}$ \\
Fathers' Education Level & $.37(.00)^{* *}$ & $.27(.00)^{* *}$ & $.27(.00)^{* *}$ & $.25(.00)^{* *}$ \\
& & & & $.44(.00)^{* *}$ \\
Home Learning & $.45(.00)^{* *}$ & $.42(.00)^{* *}$ & $.33(.00)^{* *}$ & $.40(.00)^{* *}$ \\
Parents' Literacy Involvement & $.41(.00)^{* *}$ & $.43(.00)^{* *}$ & $.30(.00)^{* *}$ & $.27(.00)^{* *}$ \\
Parents' Literacy Habit & $.23(.01)^{* *}$ & $.22(.01)^{*}$ & $.24(.01)^{* *}$ & $.32(.00)^{* *}$ \\
Children's Literacy Interest & $.39(.00)^{* *}$ & $.38(.00)^{* *}$ & $.25(.00)^{* *}$ & \\
& & & & $-.19(.03)^{*}$ \\
\hline Teachers' Teaching Experience & $-.17(.05)^{*}$ & $-.10(.25)$ & $-.21(.01)^{*}$ &
\end{tabular}

Note. ${ }^{*} p<.05,{ }^{* *} p<.01$, sex was dummy coded $(0=$ boy, $1=$ girl $)$

\subsubsection{Predictors of Preschooler's Literacy Skills}

Multiple regression analysis was utilised to determine how well the background variables (child personal characteristics, and family characteristics) and independent variables (home learning, and teachers' teaching experience) predicted the dependent variable (literacy skills). The aim of multiple regression analysis is to discover which of these variables contributed the most in the explanation of the variance in preschoolers' literacy skills. Analysis of predictors of preschooler's literacy skills is presented in Table 2. Preliminary, analysis was conducted to ensure no violation of the assumptions of normality, linearity, multicollinearity and homoscedasticity.

In the current study, only six predictors (child's age, monthly household income, mothers' education level, fathers' education level, home learning, and teachers' teaching experience) were included in the regression model in predicting preschoolers' literacy skills. The child's sex, child's birth order, and number of children variables were excluded in the following analysis because they have no significant relationship with preschoolers' literacy skills and its subscales in the bivariate analysis tested earlier. As shown in Table 2, the results suggest that the Adjusted $R^{2}$ of 0.29 implies that the six predictor variables (child's age, monthly household income, mothers' education level, fathers' education level, home learning, and teachers' teaching experience) in the equation explained about $29 \%$ of the variance in children's literacy skills $\left(R^{2}=.32, F=10.05(6,135), p<0.01\right)$. The findings indicated that home learning $(\beta=.32, p<0.01)$, mothers' education level $(\beta=.23, p<0.05)$ and teachers' teaching experience $(\beta=-.15, p<0.05)$ are important in explaining variation of preschooler's literacy skills among the five predictors. Additionally, the findings also indicated that none of the child personal characteristics (age), family characteristics (monthly household income, and fathers' education) made a unique prediction to preschoolers' literacy skills. 
Table 2. Multiple regression analyses for predicting preschooler's literacy skills from child personal characteristics, family characteristics, and home learning

\begin{tabular}{cccccc}
\hline Variables & Beta & Std. Error & $\beta$ & $t$ & $p$ \\
\hline Constant & .66 & .70 & & .94 & .35 \\
Child's Age & .05 & .12 & .03 & .41 & .68 \\
Monthly Household Income & 8.89 & .00 & .03 & .36 & .72 \\
Mothers' Education Level & .19 & .09 & $.23^{*}$ & 2.18 & .03 \\
Fathers' Education Level & .10 & .08 & .12 & 1.19 & .24 \\
Home Learning & .05 & .01 & $.32^{* *}$ & 4.04 & .00 \\
Teachers' Teaching Experience & -.04 & .02 & $-.15^{*}$ & -2.05 & .04 \\
\hline
\end{tabular}

Note. Significant level $=* p<.05, * * p<.01, F=10.05, R=0.56, R^{2}=0.32$, Adjusted $R^{2}=0.29$

\subsubsection{Moderating Effects of Teacher's Teaching Experience on Home Learning Association with Literacy Skills}

The Hierarchical Multiple Regression Analysis is presented in Table 3. Four regression steps were computed to test the moderation effect in the present study. In the first step, the background variables of children and parents (child's age, family total monthly income, number of children, fathers' education level, and mothers' education level) were entered as the control to identify the potential confounding effect on preschooler's literacy skills. The findings illustrated that $19 \%$ of the variance in preschoolers' literacy skills can be explained by the background variables $(F=7.30(5,135), p<.01)$. In the second step, the home learning variable was entered into the regression equation to determine whether the home learning is a significant predictor of child's literacy skills after taking into account the background variables. The findings indicated that there is an increase of the adjusted $R^{2}$ change of about 0.09 and the overall model explained $28 \%$ of the variance $(F=9.54(6,135), p<.01)$. This means that home learning is a significant predictor of child's literacy skills after controlling the background variables. Further, the teachers' teaching experience was added in the third step of the regression equation to determine whether teachers' teaching experience makes a significant contribution to preschooler's literacy skills while controlling the background variables and home learning variable. The findings show that there is a minimal adjusted $R^{2}$ change of $0.01,(F=8.93(7,135), p<.01)$. It can be seen that teachers' teaching experience contributes to a significant variance of preschooler's literacy skills.

The moderation effect of teachers' teaching experience on the relationship of home learning and preschoolers' literacy skills was examined in step 4 . When the product term (home learning $\mathrm{x}$ teachers' teaching experience) was entered in step 4 , the findings illustrated that the whole model explained $34 \%$ of the variance. Furthermore, there is an increase in the adjusted $R^{2}$ change of approximately 0.05 . This means that the interaction term explained an additional $5 \%$ of the variance in child's literacy skills when the main effect of the background variables, home learning environment, and teachers' teaching experience were statistically controlled. There was still a significant increment in the prediction of preschoolers' literacy skills contributed by the interaction effect of home learning and teachers' teaching experience $(F=9.50(8,135), p<0.01)$. As a conclusion, the finding provides empirical support for the moderating effect of teachers' teaching experience on the relationship between home learning and preschoolers' literacy skills.

As mentioned above, the interaction effect is evident where the interaction between home learning and teachers' teaching experience was significant on preschoolers' literacy skills. Further, the moderation effect of teachers' teaching experience on the relationship between home learning and preschoolers' literacy skills illustrated in figure 1 gave a clear visual on the underlying pattern of interaction. The figure depicted the predicted relationship between two levels of home learning (low and high) and preschoolers' literacy skills at two levels of teachers' teaching experience (low and high). Preschoolers who practice high home learning generally reported a higher level of literacy skills than those with low home learning regardless of the level of teachers' teaching experience. A closer inspection of the figure above reveals that preschoolers who practice high home learning with highly experienced teachers showed a low level of literacy skills but not when they were taught less experienced teachers. However, preschoolers who practice low home learning with highly experienced teachers compared to preschoolers with less experienced teachers have slightly higher level of literacy skills. It can be concluded that, when the model included the interaction of home learning and teachers' teaching experience, the direction of the association between home learning and children's literacy skills differed where the level of 
teachers' teaching experience in the model had weakened the association between home learning environment and children's literacy skills. This is contrary to the hypothesis propounded where there is no significant moderating effect of teachers' teaching experience on the relationship between home learning and preschoolers' literacy skills.

Table 3. Relationship between home learning and child's literacy skills moderate by teachers' teaching experience

\begin{tabular}{lcccc}
\hline \multirow{2}{*}{ Variables } & Standardized & Regression & Coefficient & $(\beta)$ \\
\cline { 2 - 5 } & Step 1 & Step 2 & Step 3 & Step 4 \\
\hline Background variables & & & & \\
Child's age & .12 & .06 & .03 & .03 \\
Family Total Monthly Income & .09 & .04 & .04 & .06 \\
Number of children & -.14 & -.11 & -.12 & -.10 \\
Fathers' Education Level & .14 & .15 & .16 & .14 \\
Mothers' Education Level & $.26^{*}$ & .18 & .19 & $.22^{*}$ \\
Home Learning Environment & & $.32^{* *}$ & $.31^{* *}$ & $.65^{* *}$ \\
Teachers' Teaching Experience & & & $-.15^{*}$ & -.14 \\
Home Learning Environment* & & & & \\
Teachers' Teaching Experience & & .28 & .29 &. $.41^{* *}$ \\
Adjusted $R^{2}$ & .19 & $9.54^{* *}$ & $8.93^{* *}$ & $9.50^{* *}$ \\
$F$ & $7.30^{* *}$ & $16.42^{* *}$ & $3.95^{*}$ & $9.41^{* *}$ \\
$F$ Change & $7.30^{* *}$ & 135 & 135 & 135 \\
$N$ & 135 & & & \\
\hline
\end{tabular}

Note. ${ }^{*} p<.05, * * p<.01$, teachers' teaching experience was dummy coded $(0=<5,1=\geq 5)$

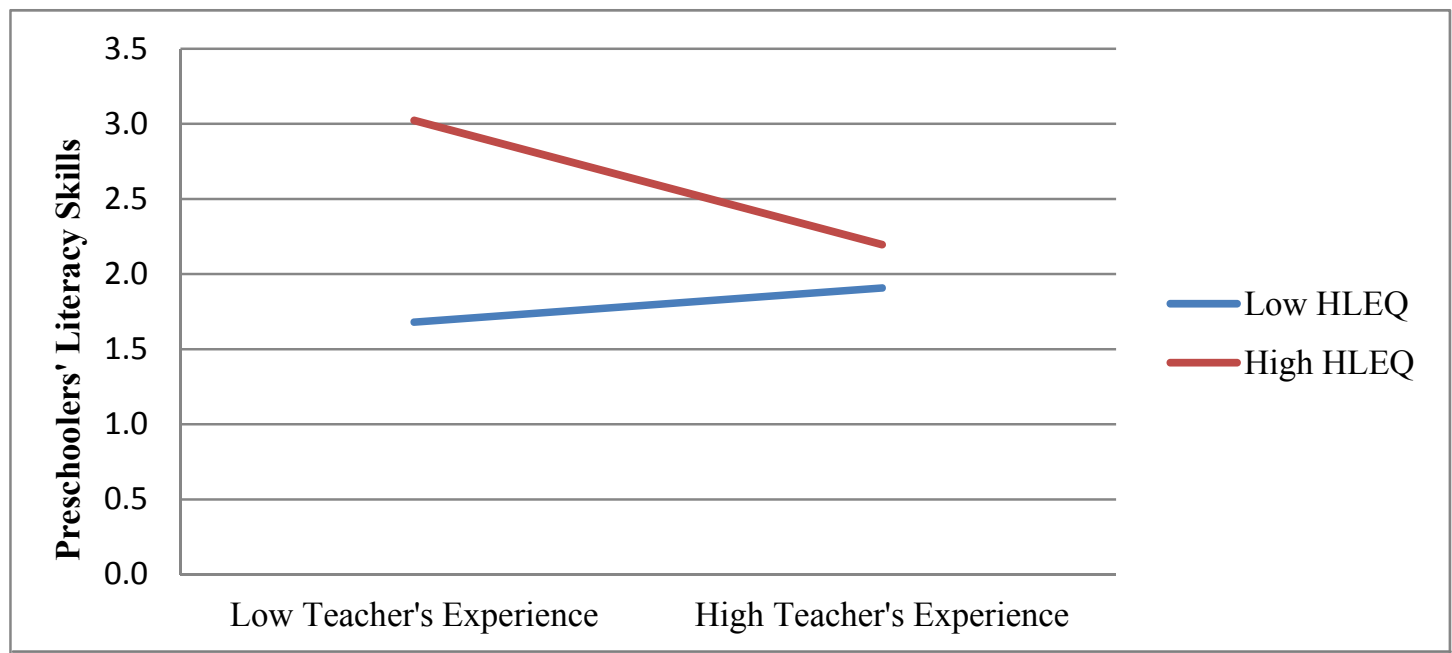

Figure 1. The moderator effect of teachers' teaching experience on the relationship between home learning and children's literacy skills

\section{Discussion}

The current study aimed to determine the predictors of preschoolers' literacy skills and moderating effects of teachers' teaching experience on home learning associated with literacy skills among Chinese preschoolers. The results of the hierarchical multiple regression analysis disclosed that the relationships between home learning 
and preschooler's literacy skills were moderated by teachers' teaching experience. The results showed that the moderating effect of teachers' teaching experience illustrated that $5 \%$ of variance in child's literacy skills increased beyond the variance explained by the home learning and teachers' teaching experience. This means that after taking into account the main effect of the antecedent variables, home learning, and teachers' teaching experience, there was still a significant increment in the prediction of children's literacy skills contributed by the interaction effect of home learning and teachers' teaching experience, consequently affecting the strength of the association between home learning and preschooler's literacy skills. This finding is align with the study by Hamre, Pianta, Burchinal and Downer (2010) determined that teachers' teaching experience is a potential moderator in the testing of children's literacy development.

Additionally, based on hierarchical regression analysis, this study found that parent's involvement in home learning practices does increase the level of literacy skills among preschoolers. When parents actively participate themselves in home learning activities, may enhance their child's literacy skills. These findings are in line with previous studies (Kim, Im, \& Kwon, 2015; Niklas \& Schneider, 2013; Farver, Xu, Lonigan, \& Eppe, 2013) that illustrated parents' involvement in home learning activities can improve the letter knowledge, phonological awareness, vocabulary, and cognitive abilities of the preschoolers.

Besides that, the study indicated that mothers' education level is the strongest predictor of preschoolers' literacy skills in comparison to other familial factors in the model. These results of the current study are sharing important consistencies with previous studies, which seem to support that higher level of mothers' education level (Silinskas, Kiuru, Tolvanen, Niemi, Lerkkanen, \& Nurmi, 2013; Zhang, 2012; Husian, Chuah, \& Mehar, 2011; Ngorosho, 2011) was associated with high level of preschooler's literacy skills. According to Silinskas et al. (2013), high educated mothers are having positive feelings about literacy and are more likely to involve in their children's learning. Thus, their child's literacy skills are outstanding than others. However, there was a weak and negative statistical correlation between teachers' teaching experience and children's literacy skills. Preschoolers who had teachers with more teaching experience tend to perform lowly in literacy skills. This is contrary to the expectation from previous studies which indicated that teachers with more experience in teaching were more effective in teaching and tend to enhance children's learning outcomes (Aro \& Bjorn, 2015; Giles \& Tunks, 2014; Son, Kwon, Jeon, \& Hong, 2013; Pakarinen, Kiuru, Lerrkanen, Poikkeus, Ahonen, \& Nurmi, 2011; Webster-Stratton, Reinke, Herman, \& Newcomer, 2011).

Overall, the findings of this study support the theory that preschooler's literacy skills may be influenced by the myriad of factors which present within the Ecological Theory (Bronfenbrenner, 1979). The results showed that the theoretical model of literacy skills for Chinese preschoolers was appropriately described by the child's age, parents' education level, monthly household income, home learning with its three sub-dimensions (parents' literacy involvement, parents' literacy habits, and child's literacy interest), and teachers' teaching experience. The focus of the present study was to examine the immediate context of the preschoolers, such as the family setting (home learning) and the community setting (teachers' teaching experience), labelled the microsystem based on the theory's terms. The literacy involvement guidance style that parents provide at home and teachers' experience in teaching may enhance the preschooler's literacy skills. Likewise, this study provides empirical evidence on the role of the home learning and teachers' teaching experience in shaping preschoolers' literacy skills.

However, there are limitations inherent in the current study where the study was only conducted among respondents in the urban ares and only focused on 136 Chinese preschoolers within the age range of three years old to six years old. Hence, the findings from this study can only be generalized to this particular population. Although it is not a representative sample of the population, the results offered by the current report are of interest to the educative community in order to reinforce preschoolers' literacy skills. Therefore, future studies are recommended to expand this study by using more diverse samples and different settings so that the results can be generalized to the whole target population.

\section{References}

Abidin, M. J. Z., Pour-Mohammadi, M., \& Ooi, C. L. (2011). The reading habits of Malaysian Chinese university students. Journal of Study in Education, 1(1).

Aro, M., \& Bjorn, P. M. (2015). Preservice and inservice teachers' knowledge of language constructs in Finland. Annals of Dyslexia, 1-16. http://dx.doi.org/10.1007/s11881-015-0118-7

Bronfenbrenner, U. (1979). The ecology of human development: Experiments by nature and design. Cambridge, MA: Harvard University Press. 
Department of Statistics, Malaysia (2010). Population distribution and basic demographic characteristics 2010. Retrieved September 4, 2012, from http://www.statistics.gov.my/portal/download_Population/files/census 2010/Taburan_Penduduk_dan_Ciri-ciri_Aras__Demografi.pdf

Department of Statistics, Malaysia (2011). Vital statistics Malaysia 2011. Retrieved April 8, 2013, from http:// www.statistics.gov.my/portal/images/stories/files/LatestReleases/vital/Vital_Statistics_Malaysia_2011.pdf

Department of Statistics, Malaysia (2012). Findings of the household income survey (HIS) 2012. Retrieved April 3, 2013, from http://www.statistics.gov.my/portal/images/stories/files/LatestReleases/household/HIS_2012_ Eng.pdf

Farver, J. A. M., Xu, Y., Lonigan, C. J., \& Eppe, S. (2013). The home literacy environment and Latino head start children's emergent literacy skills. Developmental Psychology, 49, 775-791. http://dx.doi.org/10.1037/ a0028766

Giles, R. M., \& Tunks, K. (2014). Teachers' thoughts on teaching reading: An investigation of early childhood teachers' perceptions of literacy acquisition. Journal of Early Childhood Education, 43(6). http://dx.doi.org/ $10.1007 / \mathrm{s} 10643-01400672-3$

Gullo, D. F. (2013). Improving instructional practices, policies, and student outcomes for early childhood language and literacy through data-driven decision making. Journal of Early Childhood Education, 41, 413-421. http://dx.doi.org/10.1007/s10643-013-0581-x

Hamre, B. K., Pianta, R. C., Burchinal, M., \& Downer, J. T. (2010). A course on supporting early language and literacy development through effective teacher-child interactions: Effect on teacher beliefs, knowledge and practice. Paper presented at the Annual Meeting of the Society for Research on Educational Effectiveness, Washington, DC.

Husain, F. M., Chuah, S. C., \& Singh, M. K. M. (2011). Malaysian mothers' beliefs in developing emergent literacy through reading. Social and Behavioural Sciences, 29, 846-855.

Kim, S., Im, H., \& Kwon, K. A. (2015). The role of home literacy environment in toddlerhood in development of vocabulary and decoding skills. Child Youth Care Forum, 44, 835-852. http://10.1007/s10566-015-9309-y

Leedy, P. D., \& Ormrod, J. E. (2005). Practical research: Planning and design. New Jersey: Merrit Prentice Hall.

Li, L., \& Tan, C. L. (2015). Home literacy environment and its influence on Singaporean children's Chinese oral and written language abilities. Journal of Early Childhood Education, 1-7. http://dx.doi.org/10.1007/ s10643-015-0723-4

Lonigan, C. J., \& Farver, J. M. (2002). Home literacy environment questionnaire (HLEQ). Early Childhood Research Quarterly, 21.

Lonigan, C. J., Farver, J. M., Phillips, B. M., \& Clancy-Menchetti, J. (2011). Promoting the development of preschool children's emergent literacy skills: A randomized evaluation of as literacy-focused curriculum and two professional development models. Journal of Reading and Writing, 24, 305-337. http://dx.doi.org/10.1007/s11145-009-9214-6

National Education Blueprint 2006-2010. (2010). Centre for Public Policy Studies. Retrieved September 4, 2012, from http://www.cpps.org.my/resource_centre/Education.pdf

National Reading Panel. (2000). Report of the National reading Panel: Teaching children to read. Washington, DC: U.S. Department of Health and Human Services.

National Research Council. (1998). Preventing Reading Difficulties in Young Children. Washington, DC. National Academy Press.

Ngorosho, D. (2011). Reading and writing ability in relation to home environment: A study in primary education in rural Tanzania. Child Indicators Research, 4(3), 369-388. http://dx.doi.org/10.1007/s12187-010-9089-8

Niklas, F., \& Schneider, W. (2013). Home learning environment and the beginning of reading and spelling. Contemporary Educational Psychology, 38(1), 40-50. http://dx.doi.org/10.1016/j.cedpsych.2012.10.001

Pakarinen, E., Kiuru, N., Lerkkanen, M. K., Poikkeus, A. M., Ahonen, T., \& Nurmi, J. E. (2011). Instructional predicts children's task-avoidance in kindergarten. Early Childhood Research Quarterly, 26(3), 376-386. http://dx.doi.org/10.1016/j.ecresq.2010.11.003

Performance Management and Delivery Unit. (2009). Literacy and numeracy education NKRA lab. Retrieved 
July 6, 2012, from http://pelajaranperak.gov.my/v2/modules/mastop publish/files/files4b2ed3402c1e0.pdf.

Phoon, H. S., \& Abdullah, A. C. (2010). Oral vocabulary as a predictor of English language proficiency among Malaysian Chinese preschool children. The Southeast Asian Journal of English Language Studies, 20(1), 143-156.

Reid, D. K., Hresko, W. P., \& Hammill, D. D. (2001). Test of early reading ability third edition examiner's manual. United States: Pro-Ed, Inc.

Shanahan, T., \& Shanahan, C. (2012). What is disciplinary literacy and why does it matter? Topics in Language Disorders, 32(1), 7-18.

Silinskas, G., Kiuru, N., Tolvanen, A., Niemi, P., Lerkkanen, M. K., \& Nurmi, J. E. (2013). Maternal teaching of reading and children's reading skills in Grade 1: Pattern and predictors of positive and negative associations. Learning and Individual Differences, 27, 54-66. http://dx.doi.org/10.1016/j.londof.2013.06.011

Son, S. H. C., Kwon, K. A., Jeon, H. J., \& Hong, S. Y. (2013). Head start classrooms and children's school readiness benefit from teachers' qualifications and ongoing training. Child Youth Care Forum, 42, 525-553. http://dx.doi.org/10.1007/210566-013-9213-2

Vygotsky, L. (1978). Mind in society: The development of higher psychological process. Cambridge, MA: Harvard University Press.

Webster-Stratton, C., Reinke, W. M., Herman, K. C., \& Newcomer, L. L. (2011). The incredible years teacher classroom management training: The methods and principles that support fidelity of training delivery. School Psychology Review, 40(4), 509-529.

Zhang, X. (2012). The effects of parental education and family income on mother-child relationships, father-child relationships, and family environments in the people's republic of China. Family Process, 51(4), 483-497. http://dx.doi.org/10.1111/j.1545-5300.2011.01380.x

\section{Copyrights}

Copyright for this article is retained by the author(s), with first publication rights granted to the journal.

This is an open-access article distributed under the terms and conditions of the Creative Commons Attribution license (http://creativecommons.org/licenses/by/3.0/). 